\title{
Effect of Ivabradine on Endothelial Function in Diastolic and Right Heart Failure Patients
}

\author{
Arturo Orea-Tejeda, ${ }^{1}$ Karla Balderas-Muñoz, ${ }^{1}$ Lilia Castillo-Martínez, ${ }^{1}$ \\ Oscar Infante-Vázquez, ${ }^{2}$ Raúl Martínez Memije, ${ }^{2}$ Candace Keirns-Davis, ${ }^{3}$ \\ Joel Dorantes-García, ${ }^{4}$ René Narváez-David, ${ }^{4}$ and Zuilma Vázquez-Ortíz ${ }^{4}$ \\ ${ }^{1}$ Heart Failure Clinic, Instituto Nacional de Ciencias Médicas y Nutrición Salvador Zubirán, Mexico \\ ${ }^{2}$ Instrumentation Department, Instituto Nacional de Cardiología "ICh", Mexico \\ ${ }^{3}$ Massachusetts General Hospital, Boston, MA, USA \\ ${ }^{4}$ Cardiology Department, Instituto Nacional de Ciencias Médicas y Nutrición Salvador Zubirán, Mexico
}

Correspondence should be addressed to Lilia Castillo-Martínez; caml1225@yahoo.com

Received 18 June 2013; Revised 12 August 2013; Accepted 28 August 2013

Academic Editor: Gregory Giamouzis

Copyright (C) 2013 Arturo Orea-Tejeda et al. This is an open access article distributed under the Creative Commons Attribution License, which permits unrestricted use, distribution, and reproduction in any medium, provided the original work is properly cited.

Background. Ivabradine is an If ion current inhibitor that has proved to reduce mortality in patients with systolic heart failure by slowing heart rate without decreasing myocardial contractility. Photoplethysmography is a simple, low-cost optical technique that can evaluate vascular function and detect changes in blood flow, pulse, and swelling of tissular microvascular space. Objective. To evaluate the effect of ivabradine on endothelial function by photoplethysmography in diastolic and right heart failure patients. Methodology. 15 patients were included (mean age of $78.1 \pm 9.2$ years) with optimally treated diastolic and right heart failure. They underwent photoplethysmography before and after induced ischemia to evaluate the wave blood flow on the finger, using the maximum amplitude time/total time (MAT/TT) index. Two measurements were made before and after oral Ivabradine (mean $12.5 \mathrm{mg}$ a day during 6 months of followup). Results. In the study group, the MAT/TT index was $29.1 \pm 2.2$ versus $24.3 \pm 3.2(P=0.05)$ in basal recording and $30.4 \pm 2.1$ versus $23.3 \pm 2.9(P=0.002)$, before versus after ischemia and before versus after Ivabradine intervention, respectively. Conclusions. Ivabradine administration improves endothelial function (shear stress) in diastolic and right heart failure patients.

\section{Background}

Diastolic dysfunction has been associated with symptoms of congestive heart failure in patients with preserved left ventricular ejection fraction [1]. In the largest single-center study with approximately 36,000 outpatients with normal LVEF, some authors have shown that diastolic dysfunction is an independent predictor of all-cause mortality [2].

In outpatients with heart failure with preserved ejection fraction (HFpEF) at the baseline echocardiogram, worsening of diastolic function in a follow-up study is also an independent predictor of all-cause mortality [3]. In addition, Achong showed that improvement in diastolic function was associated with increased survival $(P=0.05)$ in a mixed cohort of inpatients and outpatients with normal or mild systolic dysfunction [4], while the more advanced the stage is, the higher the filling pressures and the worse the outcomes are [5].

In patients with atrial fibrillation, if diastolic function was assessed, it was based on deceleration time of mitral E-wave velocity and tissue Doppler imaging (i.e., peak early mitral inflow velocity/diastolic early tissue velocity $\left.\left[\mathrm{E} / \mathrm{e}^{\prime}\right]\right)[6]$.

Ivabradine added to recommended treatment, improved the outcome of heart failure patients reducing cardiovascular death and hospitalizations rate [7]. In patients with coronary disease and left ventricular dysfunction also the benefit was observed [8]. In experimental studies, ivabradine have been demonstrated that reduces fibrosis and improve endothelial function [9-12]. 
Ivabradine also has demonstrated a favorable effect on LV remodeling after 8 months of followup as well as and antianginal effect [13].

Hyperemic coronary blood flow velocity also increases after ivabradine treatment, probably because the diastolic period is prolonged (per cardiac beat and per minute). It has been speculated that the most probable explanation of the improvement of ventricular relaxation caused by ivabradine treatment could be its effect on coronary blood flow velocity during hyperemia [14].

To evaluate the effect of ivabradine on endothelial function by photoplethysmography in patients with right heart failure and preserved ejection fraction, we performed this open-label clinical trial.

\section{Methods}

2.1. Study Population. This open-label clinical trial included ambulatory patients who came to the Heart Failure Clinic of the Instituto Nacional de Ciencias Médicas y Nutrición "Salvador Zubirán." Patients were recruited if they were men or nongravid women with more than 18 years of age with a confirmed diagnosis of stable heart failure with preserved ejection fraction in New York Heart Association functional classes II to III. Candidates were excluded if they had had myocardial infarction, unstable angina or a history of myocardial revascularization (percutaneous transluminal coronary angioplasty or aortocoronary bypass grafts), cerebrovascular events during the previous 3 months, dysfunctional prosthetic heart valve, obstructive or nonobstructive cardiomyopathy, uncorrected congenital heart disease, active myocarditis, a history of resuscitation from sudden death, or severe arrhythmias.

Heart failure was established by signs and symptoms as well as echocardiographic and radioisotopic ventriculography findings. Preserved ejection fraction was defined as a left ventricular ejection fraction $\geq 50 \%$, LVEDVI $<97 \mathrm{~mL} / \mathrm{m}^{2}$, left atrial diameter $>40 \mathrm{~mL} / \mathrm{m}^{2}$, tissue doppler $\mathrm{E} / \mathrm{E}^{\prime}>15$ echo-blood flow Doppler E/A in $>50$ years $<0.5$, and DT in $>50$ years $>280 \mathrm{~ms}$ [15]. Right ventricular dysfunction was defined as ejection fraction $\leq 35 \%$ measured by radioisotopic ventriculography $[16,17]$.

All patients received standard heart failure therapy and their comorbidities (diuretics, angiotensin-converting enzyme inhibitors, angiotensin II antagonists, aldosterone receptor blockers, digitalis, and beta-adrenoreceptor blockers), at their maximum doses tolerated. Some patients that developed atrial fibrillation also received digital.

2.2. Study Design. This was an investigator-initiated, single center, single-arm, open-label clinical trial.

After baseline measurements, in addition to conventional therapy, patients received an average of ivabradine $12.5 \mathrm{mg}$ (10-15 mg) a day, according their tolerance during 6 months of follow-up $[18,19]$. Patients underwent 2D and Doppler echocardiograms and radioisotopic (rest/effort) left and right ventriculography before and after oral ivabradine.
TABLE 1: Demographic and clinical characteristics of the CHF patients.

\begin{tabular}{lc}
\hline Variables & $N=15$ \\
\hline Age (years) & $78.1 \pm 9.2$ \\
Female (\%) & 73.3 \\
Arterial hypertension (\%) & 73.3 \\
Hypothyroidism (\%) & 53.3 \\
Diabetes mellitus (\%) & 33.3 \\
COPD (\%) & 33.3 \\
Dyslipidemia (\%) & 26.6 \\
End Stage Kidney disease (\%) & 26.6 \\
Functional class (NYHA): & \\
$\quad$ II & 60 \\
$\quad$ III & 40 \\
\hline
\end{tabular}

2.2.1. Photoplethysmography. A baseline digital photoplethysmographic wave was recorded for 30 seconds. The forearm was then compressed with a sphygmomanometer cuff for 5 minutes using a pressure of $30 \mathrm{mmHg}$ above the systolic arterial pressure recorded (ischemic phase). The compression was then released and the digital photoplethysmographic wave was recorded for 120 seconds. The wave was analyzed at 30-second intervals for comparison with the baseline values. The most representative waves were selected from the recording of each interval, and the maximum amplitude time (MAT) and total time (TT) were measured in order to calculate the MAT/TT index. A MAT/TT index of less than 30 was considered normal, as proposed in other studies [20, 21].

Cardiologists who performed the echocardiograms and radioventriculography did not have access to patients' information.

2.3. Statistical Analysis. Continuous variables were expressed as mean \pm standard deviation (SD) and categorical variables as percentages. To compare the changes from baseline to 6 months, a paired $t$-test was used. A $P$ value of $<0.05$ was considered statistically significant. All analyses were performed using a commercially available package (SPSS for Windows, version 17.0 SPSS Inc.).

\section{Results}

Fifteen patients (73.6\% female) were studied. Arterial hypertension and hypothyroidism (under treatment and well controlled) were the most common comorbidities with patients in functional classes (NYHA) II and III (Table 1). It is important to note that COPD and ESKD patients were not excluded from the study. Concomitant medication was as follows: diuretic (73\%) and adrenergic beta blocker receptor $(\mathrm{BB}, 73 \%)$ agents were the most commonly employed; $46.6 \%$ also received mineralocorticoid receptor antagonists (MRAmedications) and angiotensin-convertingenzyme inhibitors (ACEIs)/angiotensin receptors blockers (ARB). 


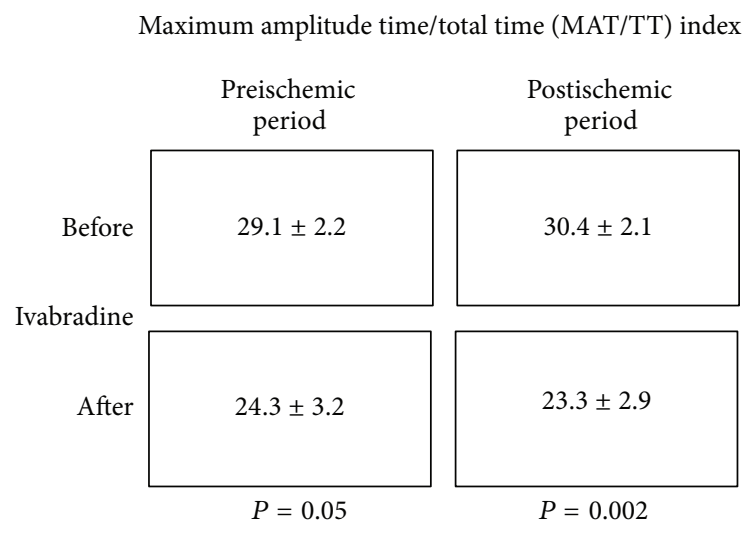

FIGURE 1: Pre and after ischemic period, before and after 6 months of follow-up of oral ivabradine.

Patients received an average of 12.5 (range 10-15) mg/day during the 6 months of followup. It was particularly interesting that heart rate did not decrease in any patients below the $10 \%$ recommended ( 88 versus 82 beats $/ \mathrm{min}$ ) in the literature in spite of the top doses received.

Figure 1 shows the maximum amplitude time/total time (MAT/TT) index before and after the followup. A significant increase in pre- and post-ischemic periods after ivabradine administration is evident when basal values are compared with those at the end of followup.

Improvement of the endothelial-dependent vasodilatation expressed by significant changes observed in the photoplethysmographic curves occurred concurrently. All patients had some degree of clinical improvement, $8 / 9$ (88.8\%) from NYHA III to II and 4/6 (66.6\%) from II to I, respectively, although this did not achieve statistical significance $(P=$ $0.08)$.

With respect to cardiac structural changes, in the echocardiographic study, only right ventricular diastolic diameter (40.5 \pm 7.8 versus $36.4 \pm 5.3 ; P=0.05$ ) was significantly different after the followup. There was also a reduction of $8.15 \%$ in the systolic pulmonary arterial pressure $(59.6 \pm 8.4$ versus $54.9 \pm 10.2 ; P=0.05)$.

\section{Discussion}

Approximately $50 \%$ of patients with heart failure (HF) have normal or preserved left ventricular ejection fraction (HFPEF) [22], and their prognosis is similar to that of patients with HF with reduced LVEF (HFREF) [22, 23]. Left ventricular diastolic dysfunction (LVDD) plays an important role in patients with HFPEF [24] and could be due to structural and molecular abnormalities of the cardiovascular system. These abnormalities include myocardial ischemia, cardiac hypertrophy, cardiac inflammation [25], and ventricular vascular stiffening, in part due to the reduced effects of nitric oxide and impaired endothelial function [26]. Borlaug et al. recently demonstrated that global cardiovascular reserve functions, including endothelial function, are impaired in subjects with HFNEF who have hypertension, a very frequent cause of HF [27]. In HFREF, coronary endothelial function is also impaired [28], and it has been reported that peripheral endothelial dysfunction is associated with the severity of $\mathrm{HF}$ symptoms and clinical outcome in patients with HFREF [29, 30]. Moreover, vascular stiffness and resistance with elevated blood pressure has been proposed as a potential important noncardiac factor in patients with HFpEF [31].

Endothelial dysfunction has been shown to be involved in the pathogenesis of HF, mainly HFREF. Several studies have reported that peripheral endothelial dysfunction is associated with the clinical outcome in patients with HFREF [30]. Borlaug et al. recently reported that subjects with HFpEF had limited arterial vasodilator response to exercise, which might impair cardiac output reserve under stress [32].

Peripheral endothelial function is impaired in patients with HFpEF, and when it is evaluated as a reactive hyperemia by peripheral arterial tonometry (RH-PAT), it significantly correlates with future cardiovascular events. Peripheral endothelial function is thus an independent predictor after adjusting various clinical parameters [33]. Indeed, the prognostic impact of the reactive hyperemia index in patients with HFpEF suggests that endothelial dysfunction may not be a passive finding, but may rather play an active and important pathophysiologic role in HFpEF [32]. When matched in patients and controls for diabetes and hypertension, more endothelial dysfunction was found in patients with HFPEF, who were notably more obese than controls [34].

The results of the systolic heart failure treatment with the If inhibitor ivabradine trial (SHIFT) showed that treatment with ivabradine added to conventional therapy for HF was associated with an $18 \%$ reduction in the relative risk for the primary composite endpoint of cardiovascular death or hospitalization for worsening $\operatorname{HF}(P<0.0001)$ [7]. It also had a positive effect on LV remodelling in the echocardiographic substudy of the BEAUTIFUL (morBidity-mortality EvAlUaTion of the If inhibitor ivabradine in patients with coronary disease and left ventricULar dysfunction) study [8].

In experimental studies, ivabradine has been demonstrated to reduces fibrosis and improve endothelial function [9-12], together with its antiischemic and antianginal effects [13] which could explain why all our patients improved their functional class, possibly associated with increased hyperemic coronary blood flow velocity. It may also be explained by the prolonged diastolic period (per cardiac beat and per minute). Moreover, we can speculate that the endothelial-dependent vasodilatation expressed by the significant changes observed in the photoplethysmographic curves in peripheral and coronary territories plays an important role in improving coronary blood reserve as has already been described $[35,36]$, and flow velocity may have a direct effect on coronary vessels and reduced ventricular wall tension, with improvement of ventricular relaxation [14], added to diminished right ventricular diastolic diameter with significant reduction of arterial pulmonary pressure, which probably reflects improved coronary perfusion pressure (aortic mean pressure/coronary sinus ratio).

In experimental postinfarction settings, both cardiac [37] and pulmonary vascular [38] endothelial dysfunction may 
contribute to the development of heart failure through endocardial and myocardial capillary endothelial abnormalities [39] and could explain the impaired left ventricular relaxation in pressure-overload hypertrophy [40].

Preserved ejection fraction is present in almost 50\% of heart failure patients and is cause of half of HF hospitalizations, and traditional HF treatment is not effective. A recently published pathophysiology-based novel pharmacotherapy for these patients considers spironolactone, aliskiren, and neprilisyn as therapeutic options for HFPEF because of their anti-hypertrophic and anti-fibrotic effects [41]. Combined ventricular and vascular stiffening involving both the systemic and pulmonary circulations, plays a role in the pathophysiology of HFpEF [42, 43]. Thus, the effects of ivabradine on endothelial function, that we observed, may represent a major advantage when it is used to treat left diastolic dysfunction because of its secondary impact on pulmonary arterial hypertension and damaged right ventricular function.

\section{Limitations}

The number of patients studied was small, and the intervention period was short. It is probable that a longer followup would show changes in variables such as left ventricular diastolic diameter and other structural characteristics. In addition, the lack of direct quantification of pulmonary pressures is a drawback.

Our findings support continued investigation into the effects of ivabradine on right ventricular function, systemic arterial pressure, and systolic pulmonary arterial pressure in heart failure patients with preserved ejection fraction. More studies are required to evaluate the effects observed on a larger number of patients for a longer period.

\section{References}

[1] W. Aljaroudi, M. C. Alraies, C. Halley et al., "Impact of progression of diastolic dysfunction on mortality in patients with normal ejection fraction," Circulation, vol. 125, no. 6, pp. 782-788, 2012.

[2] M. Senni, C. M. Tribouilloy, R. J. Rodeheffer et al., "Congestive heart failure in the community: a study of all incident cases in Olmsted County, Minnesota, in 1991," Circulation, vol. 98, no. 21, pp. 2282-2289, 1998.

[3] B. G. Angeja and W. Grossman, "Evaluation and management of diastolic heart failure," Circulation, vol. 107, no. 5, pp. 659-663, 2003.

[4] P. M. Mottram and T. H. Marwick, "Assessment of diastolic function: what the general cardiologist needs to know," Heart, vol. 91, no. 5, pp. 681-695, 2005.

[5] C. M. Halley, P. L. Houghtaling, M. K. Khalil, J. D. Thomas, and W. A. Jaber, "Mortality rate in patients with diastolic dysfunction and normal systolic function," Archives of Internal Medicine, vol. 171, no. 12, pp. 1082-1087, 2011.

[6] H. Okura, Y. Takada, T. Kubo et al., “Tissue Doppler-derived index of left ventricular filling pressure, $\mathrm{E} / \mathrm{E}^{\prime}$, predicts survival of patients with non-valvular atrial fibrillation," Heart, vol. 92, no. 9, pp. 1248-1252, 2006.
[7] K. Swedberg, M. Komajda, M. Böhm et al., "Ivabradine and outcomes in chronic heart failure (SHIFT): a randomised placebo-controlled study," The Lancet, vol. 376, no. 9744, pp. 875-885, 2010, Erratum in The Lancet, vol. 376, p. 1988, 2010.

[8] C. Ceconi, S. B. Freedman, J. C. Tardif et al., "Effect of heart rate reduction by ivabradine on left ventricular remodeling in the echocardiographic substudy of BEAUTIFUL," International Journal of Cardiology, vol. 146, no. 3, pp. 408-414, 2011.

[9] P. Mulder, S. Barbier, A. Chagraoui et al., "Long-term heart rate reduction induced by the selective If current inhibitor ivabradine improves left ventricular function and intrinsic myocardial structure in congestive heart failure," Circulation, vol. 109, no. 13, pp. 1674-1679, 2004.

[10] E. I. Dedkov, W. Zheng, L. P. Christensen, R. M. Weiss, F. Mahlberg-Gaudin, and R. J. Tomanek, "Preservation of coronary reserve by ivabradine-induced reduction in heart rate in infarcted rats is associated with decrease in perivascular collagen," American Journal of Physiology-Heart and Circulatory Physiology, vol. 293, no. 1, pp. H590-H598, 2007.

[11] P. Milliez, S. Messaoudi, J. Nehme, C. Rodriguez, J.-L. Samuel, and C. Delcayre, "Beneficial effects of delayed ivabradine treatment on cardiac anatomical and electrical remodeling in rat severe chronic heart failure," American Journal of PhysiologyHeart and Circulatory Physiology, vol. 296, no. 2, pp. H435H441, 2009.

[12] M. Vercauteren, J. Favre, P. Mulder, F. Mahlberg-Gaudin, C. Thuillez, and V. Richard, "Protection of endothelial function by long-term heart rate reduction induced by ivabradine in a rat model of chronic heart failure," European Heart Journal, vol. 28, supplement, p. 48, 2007.

[13] G. Riccioni, N. Vitulano, and N. D’Orazio, "Ivabradine: beyond heart rate control," Advances in Therapy, vol. 26, no. 1, pp. 12-24, 2009.

[14] E. I. Skalidis, M. I. Hamilos, G. Chlouverakis, E. A. Zacharis, and P. E. Vardas, "Ivabradine improves coronary flow reserve in patients with stable coronary artery disease," Atherosclerosis, vol. 215, no. 1, pp. 160-165, 2011.

[15] W. J. Paulus, C. Tschöpe, J. E. Sanderson et al., "How to diagnose diastolic heart failure: a consensus statement on the diagnosis of heart failure with normal left ventricular ejection fraction by the Heart Failure and Echocardiography Associations of the European Society of Cardiology," European Heart Journal, vol. 28, no. 20, pp. 2539-2550, 2007.

[16] N. F. Voelkel, R. A. Quaife, L. A. Leinwand et al., "Right ventricular function and failure: report of a National Heart, Lung, and Blood Institute working group on cellular and molecular mechanisms of right heart failure," Circulation, vol. 114, no. 17, pp. 1883-1891, 2006.

[17] J. F. Setaro, M. W. Cleman, and M. S. Remetz, "The right ventricle in disorders causing pulmonary venous hypertension," Cardiology Clinics, vol. 10, no. 1, pp. 165-183, 1992.

[18] F. M. Sarullo, G. Fazio, D. Puccio et al., "Impact of "off-label" use of ivabradine on exercise capacity, gas exchange, functional class, quality of life, and neurohormonal modulation in patients with ischemic chronic heart failure," Journal of Cardiovascular Pharmacology and Therapeutics, vol. 15, no. 4, pp. 349-355, 2010.

[19] A. Schuster and W. H. W. Tang, "Ivabradine in heart failure: to SHIFT or not to SHIFT," Current Heart Failure Reports, vol. 8, no. 1, pp. 1-3, 2011.

[20] J. T. Kuvin, A. R. Patel, K. A. Sliney et al., "Assessment of peripheral vascular endothelial function with finger arterial 
pulse wave amplitude," American Heart Journal, vol. 146, no. 1, pp. 168-174, 2003.

[21] A. Aldama, H. Álvarez, A. Rodríguez, and B. Reyes, "Evaluación cualitativa de la morfología de la señal fotopletismográfica en el diagnóstico de la insuficiencia arterial," Revista Cubana de Investigaciones Biomédicas, vol. 27, no. 1, 2008.

[22] R. S. Bhatia, J. V. Tu, D. S. Lee et al., "Outcome of heart failure with preserved ejection fraction in a population-based study," The New England Journal of Medicine, vol. 355, no. 3, pp. 260269, 2006.

[23] T. E. Owan, D. O. Hodge, R. M. Herges, S. J. Jacobsen, V. L. Roger, and M. M. Redfield, "Trends in prevalence and outcome of heart failure with preserved ejection fraction," The New England Journal of Medicine, vol. 355, no. 3, pp. 251-259, 2006.

[24] M. R. Zile, C. F. Baicu, and W. H. Gaasch, "Diastolic heart failure: abnormalities in active relaxation and passive stiffness of the left ventricle," The New England Journal of Medicine, vol. 350, no. 19, pp. 1953-1959, 2004.

[25] J. Matsubara, S. Sugiyama, T. Nozaki et al., "Pentraxin 3 is a new inflammatory marker correlated with left ventricular diastolic dysfunction and heart failure with normal ejection fraction," Journal of the American College of Cardiology, vol. 57, no. 7, pp. 861-869, 2011.

[26] M. Ouzounian, D. S. Lee, and P. P. Liu, "Diastolic heart failure: mechanisms and controversies," Nature Reviews Cardiology, vol. 5, pp. 375-386, 2008.

[27] B. A. Borlaug, T. P. Olson, C. S. P. Lam et al., "Global cardiovascular reserve dysfunction in heart failure with preserved ejection fraction," Journal of the American College of Cardiology, vol. 56, no. 11, pp. 845-854, 2010.

[28] S. H. Kubo, T. S. Rector, A. J. Bank, R. E. Williams, and S. M. Heifetz, "Endothelium-dependent vasodilation is attenuated in patients with heart failure," Circulation, vol. 84, no. 4, pp. 15891596, 1991.

[29] M. A. AlZadjali, V. Godfrey, F. Khan et al., "Insulin resistance is highly prevalent and is associated with reduced exercise tolerance in non-diabetic patients with heart failure," Journal of the American College of Cardiology, vol. 53, no. 9, pp. 747-753, 2009.

[30] D. Fischer, S. Rossa, U. Landmesser et al., "Endothelial dysfunction in patients with chronic heart failure is independently associated with increased incidence of hospitalization, cardiac transplantation, or death," European Heart Journal, vol. 26, no. 1, pp. 65-69, 2005.

[31] G. Cotter, M. Metra, O. Milo-Cotter, H. C. Dittrich, and M. Gheorghiade, "Fluid overload in acute heart failure-re-distribution and other mechanisms beyond fluid accumulation," European Journal of Heart Failure, vol. 10, no. 2, pp. 165-169, 2008.

[32] B. A. Borlaug, V. Melenovsky, S. D. Russell et al., "Impaired chronotropic and vasodilator reserves limit exercise capacity in patients with heart failure and a preserved ejection fraction," Circulation, vol. 114, no. 20, pp. 2138-2147, 2006.

[33] E. Akiyama, S. Sugiyama, Y. Matsuzawa et al., "Incremental prognostic significance of peripheral endothelial dysfunction in patients with heart failure with normal left ventricular ejection fraction," Journal of the American College of Cardiology, vol. 60, no. 18, pp. 1778-1786, 2012.

[34] C. S. Lam and D. L. Brutsaert, "Endothelial dysfunction: a pathophysiologic factor in heart failure with preserved ejection fraction," Journal of the American College of Cardiology, vol. 60, no. 18, pp. 1787-1789, 2012.
[35] M. B. Britten, A. M. Zeiher, and V. Schächinger, "Microvascular dysfunction in angiographically normal or mildly diseased coronary arteries predicts adverse cardiovascular long-term outcome," Coronary Artery Disease, vol. 15, no. 5, pp. 259-264, 2004.

[36] B. A. Herzog, L. Husmann, I. Valenta et al., "Long-term prognostic value of $13 \mathrm{~N}$-ammonia myocardial perfusion positron emission tomography added value of coronary flow reserve," Journal of the American College of Cardiology, vol. 54, no. 2, pp. 150-156, 2009.

[37] X.-L. Qi, D. J. Stewart, H. Gosselin et al., "Improvement of endocardial and vascular endothelial function on myocardial performance by captopril treatment in postinfarct rat hearts," Circulation, vol. 100, no. 12, pp. 1338-1345, 1999.

[38] A. Ben Driss, C. Devaux, D. Henrion et al., "Hemodynamic stresses induce endothelial dysfunction and remodeling of pulmonary artery in experimental compensated heart failure," Circulation, vol. 101, no. 23, pp. 2764-2770, 2000.

[39] D. Popov, A. Sima, D. Stern, and M. Simionescu, "The pathomorphological alterations of endocardial endothelium in experimental diabetes and diabetes associated with hyperlipidemia," Acta Diabetologica, vol. 33, no. 1, pp. 41-47, 1996.

[40] P. A. MacCarthy and A. M. Shah, "Impaired endotheliumdependent regulation of ventricular relaxation in pressureoverload cardiac hypertrophy," Circulation, vol. 101, no. 15, pp. 1854-1860, 2000.

[41] D. M. Konstantinou, Y. S. Chatzizisis, and G. D. Giannoglou, "Pathophysiology-based novel pharmacotherapy for heart failure with preserved ejection fraction," Pharmacology \& Therapeutics, 2013.

[42] C. S. P. Lam, V. L. Roger, R. J. Rodeheffer et al., "Cardiac structure and ventricular-vascular function in persons with heart failure and preserved ejection fraction from Olmsted County, Minnesota," Circulation, vol. 115, no. 15, pp. 1982-1990, 2007.

[43] C. S. P. Lam, V. L. Roger, R. J. Rodeheffer, B. A. Borlaug, F. T. Enders, and M. M. Redfield, "Pulmonary hypertension in heart failure with preserved ejection fraction: a communitybased study," Journal of the American College of Cardiology, vol. 53, no. 13, pp. 1119-1126, 2009. 


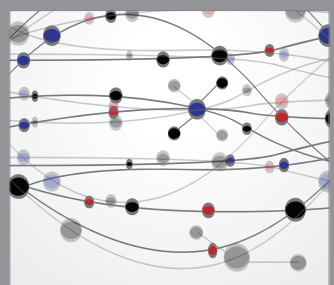

The Scientific World Journal
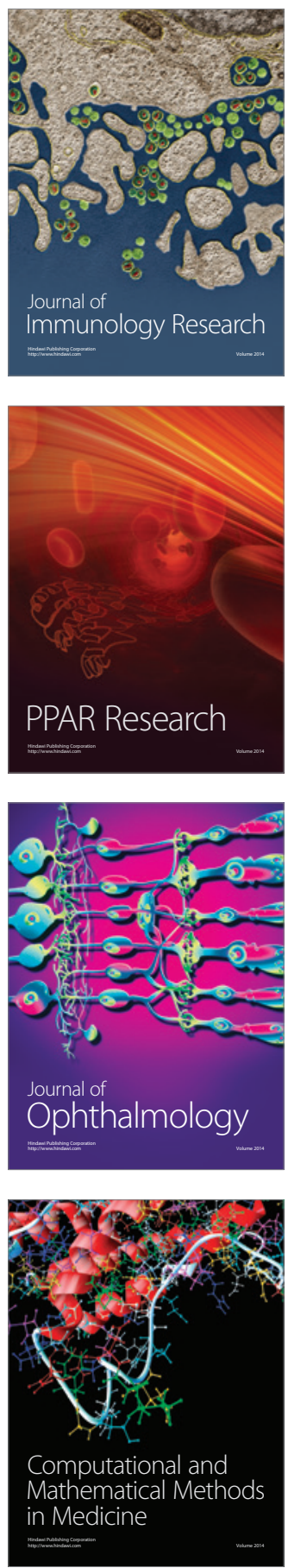

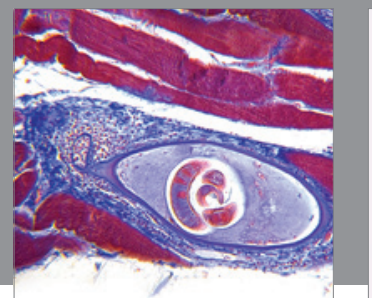

Gastroenterology

Research and Practice
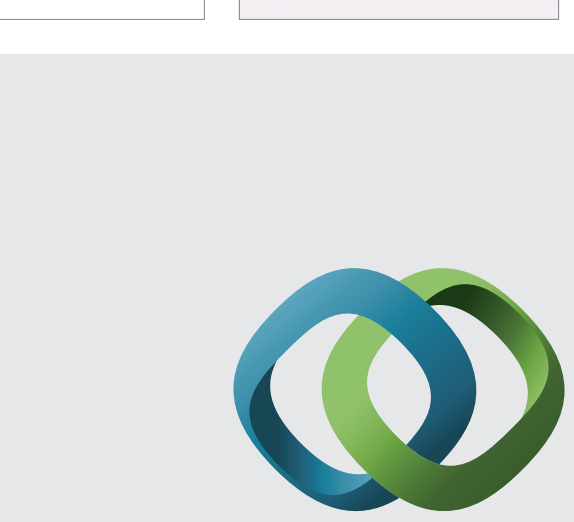

\section{Hindawi}

Submit your manuscripts at

http://www.hindawi.com
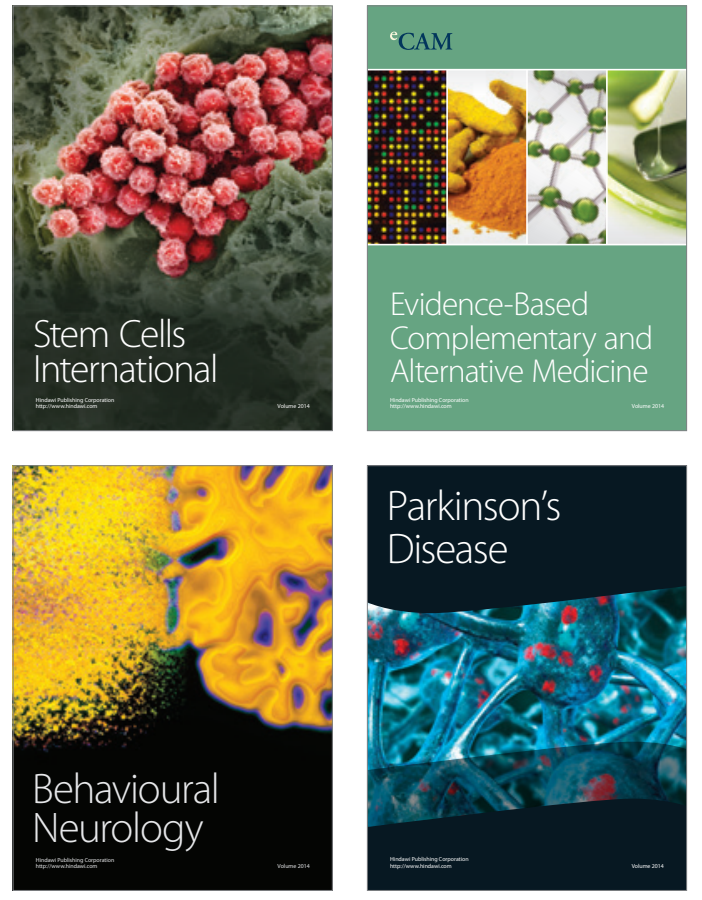
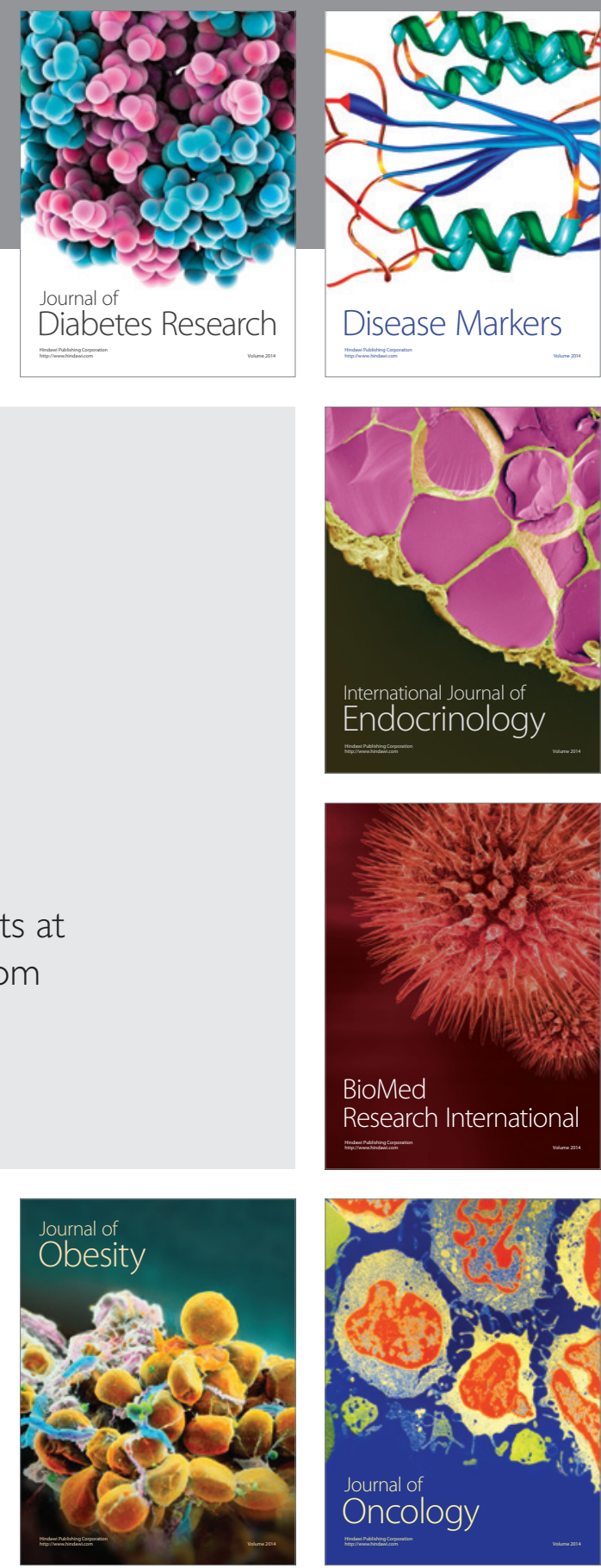

Disease Markers
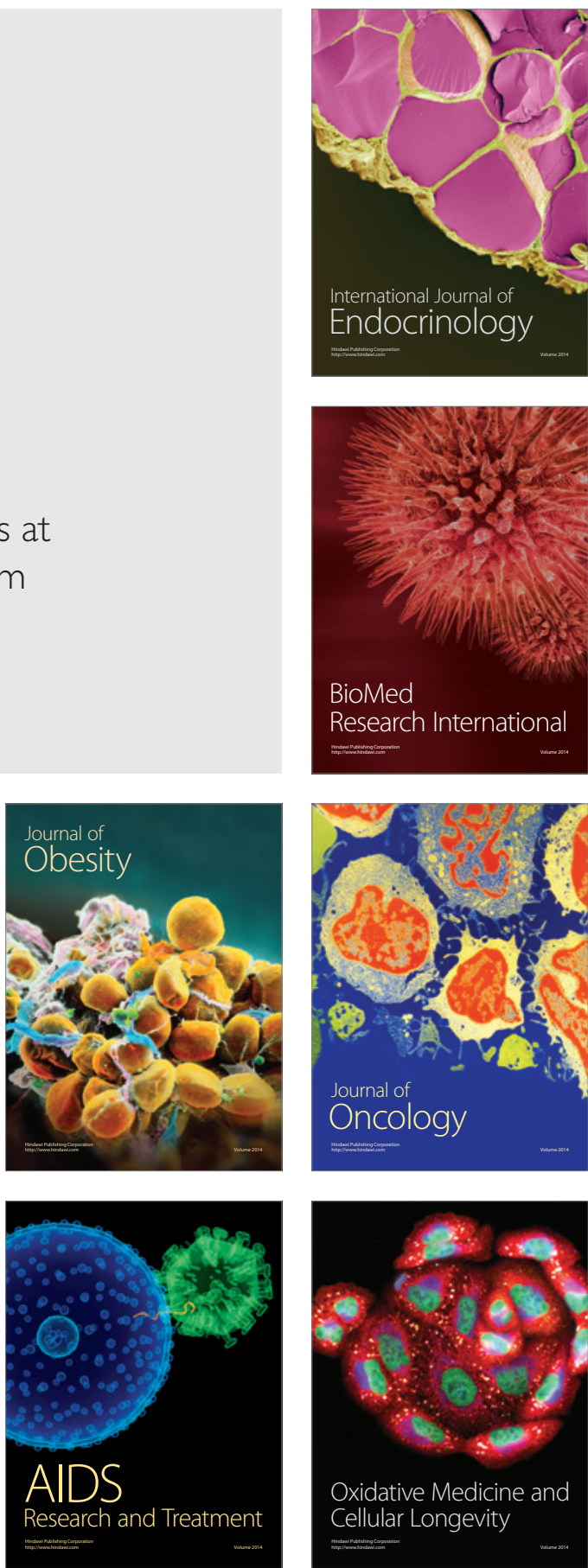